\title{
BOUNDARY VALUE PROBLEMS ASSOCIATED WITH PERTURBED NONLINEAR SYLVESTER SYSTEMS - EXISTENCE AND UNIQUENESS
}

\author{
DONALD W. FAUSETT, KANURI N. MURTY
}

Abstract. This paper is concerned with the existence and uniqueness of solutions to the boundary value problem associated with the general first-order linear/nonlinear Sylvester system

$$
R^{\prime}(t)=A(t) R(t)+R(t) B(t)+F(t, R(t)),
$$

where the matrices involved are of appropriate dimensions and are continuous on some interval $[0, T]$, and $F \in C\left[[0, T] \times R^{n \times n}, R^{n \times n}\right]$. The boundary conditions considered are of the form

$$
U R=\alpha,
$$

where $U: C[0, T] \mapsto R^{n \times n}$, and $C[0, T]$ is the space of all continuous bounded functions $f:[0, T] \mapsto R^{n \times n}$.

Mathematics subject classification (2000): 15A69, 34B05, 34B15, 65F05.

Key words and phrases: Sylvester systems, boundary value problems, Kronecker product of matrices.

\section{REFERENCES}

[1] R. H. Cole, Theory of Ordinary Differential Equations, Appleton-Century-Crofts (1968).

[2] A. JAMESON, Solution of the equation $A X+X B=C$ by inversion of an $(m \times m)$ or $(n \times n)$ matrix, SIAM Journal of Applied Mathematics, 16, 5 (1968), 1020-1023.

[3] V. Lakshmikantham, S. G. DeO, Method of Variation of Parameters for Dynamic Systems, Gordon and Breach Scientific Publishers (1998).

[4] K. N. Murty, L. V. FAUSETT, Some Fundamental Results on Controllability, Observability and Realizability of First-order Matrix Lyapunov Systems, Mathematical Sciences Research Journal, 6, 3 (2002), 147-160.

[5] K. N. Murty, G. Howell And S. Sivasundaram, Two (multi-)point non-linear Lyapunov systems, existence and uniqueness, Journal of Mathematical Analysis and Applications, 167, (1992), 505-515.

[6] G. W. Stewart, R. H. Bartels, A Solution of the equation $A X+X B=C$, Communications of the ACM, 15, 9 (1976), 820-26. 